\title{
Systematic review of the design, implementation and effectiveness of mass media and nutrition education interventions for infant and young child feeding
}

\author{
Matthew M Graziose ${ }^{1, *}$, Shauna M Downs ${ }^{2}$, Quentin $\mathrm{O}^{\prime}$ Brien $^{3}$ and Jessica Fanzo ${ }^{4}$ \\ 'Department of Health and Behavior Studies, Teachers College Columbia University, 525 West 120th Street, Box \\ 137, New York, NY 10027, USA: ${ }^{2}$ Department of Health Systems and Policy, Rutgers School of Public Health, New \\ Brunswick, NJ, USA: ${ }^{3}$ Mailman School of Public Health, Columbia University, New York, NY, USA: ${ }^{4}$ Berman Institute \\ of Bioethics and the School of Advanced International Studies, Johns Hopkins University, Baltimore, MD, USA
}

Submitted 9 August 2016: Final revision received 31 March 2017: Accepted 21 August 2017: First published online 300 0ctober 2017

\begin{abstract}
Objective: To systematically review the design, implementation and effectiveness of mass media and nutrition education interventions for improving infant and young child feeding (IYCF) practices and related psychosocial factors.

Design: A search of PubMed, Embase and PsycINFO databases, a Google search, and a consultation with experts in the field of IYCF performed in July 2016.

Setting: Low- and middle-income countries, as defined by the World Bank Group. Subjects: Eligible studies: included a mass media component (with or without nutrition education); conducted a pre-post evaluation (with or without a control group); assessed IYCF knowledge, attitudes, beliefs and/or practices; and were published in English between 2000 and present.

Results: Eighteen unique studies were identified that examined the effect of mass media (types included: television; print; voice and/or SMS (text) messages; radio; megaphones/loudspeakers; videos; social media; songs/dramas) and nutrition education interventions on IYCF practices within thirteen countries. Of these, fifteen studies reported improvements in breast- and/or complementary feeding practices, using indicators recommended by the WHO, and six studies reported improvements in related psychosocial factors. However, little detail was provided on the use of formative research, a formal behaviour change theory and behaviour change techniques. Few studies reported both dose delivered and participants' exposure to the intervention.

Conclusions: Despite evidence of effectiveness, few common elements in the design of interventions were identified. Future research should consistently report these details to open the 'black box' of IYCF interventions, identify effective design components and ensure replicability.
\end{abstract}

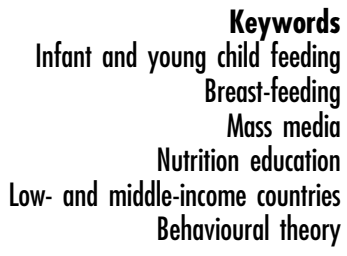

Malnutrition is a major public health problem in many low- and middle-income countries (LMIC). Currently, 159 million children $<5$ years of age suffer from stunting and 50 million from wasting ${ }^{(1)}$, which contributes to nearly one-third of all deaths of children in this age group worldwide ${ }^{(2)}$. Disparities in the prevalence of malnutrition are evident across geographic regions and wealth strata, with rural and poor children at increased risk $^{(2)}$. Nutritional inadequacies in early childhood are associated with poor physical growth, increased risk for overweight, obesity and non-communicable diseases, and reduced educational attainment and economic productivity $^{(2,3)}$.

The first $1000 \mathrm{~d}$ of life are critical for ensuring optimal growth and development and reducing the likelihood of morbidity and mortality ${ }^{(2)}$. The use of appropriate, evidence-based infant and young child feeding (IYCF) practices (Box 1) is listed among the WHO's essential nutrition actions for improving infant and child health and preventing malnutrition ${ }^{(4)}$. However, caregivers in LMIC may employ inappropriate IYCF practices due to several psychosocial factors, such as a 
Box 1 Definition of key terms used in the present systematic review of mass media and nutrition education interventions for infant and young child feeding in low- and middle-income countries

1. Nutrition education: any combination of educational strategies, accompanied by environmental supports, designed to facilitate voluntary adoption of food choices and other food- and nutrition-related behaviours conducive to health and well-being. Nutrition education is delivered through multiple venues and involves activities at the individual, community and policy levels ${ }^{(10)}$. While we use the term nutrition education, previous authors have suggested that the term 'behaviour change communication' or 'social and behaviour change communication' is interchangeable $\mathrm{e}^{(10,52)}$.

2. Behaviour change technique (also called strategy or procedure): an observable, replicable and irreducible component of an intervention designed to alter or redirect causal processes that regulate behaviour $^{(10,55)}$.

3. Formative research: a general term describing any qualitative or quantitative methods of inquiry conducted for programme design and planning.

4. Infant and young child feeding (IYCF) practices: a set of recommended behaviours to guide the feeding of children from 0 to 24 months of age including: exclusive breast-feeding; appropriate and timely introduction of safe, nutritious complementary foods; and the proper preparation of infant foods and/or use of micronutrient supplements ${ }^{(56)}$.

5. Mass media and information communication technology: any technology serving the purpose of gathering, processing and disseminating information, or supporting the process of communication ${ }^{(48,57)}$. These include, but are not limited to, radio, television, phones, email, blogs, social networking websites and print media.

6. Dose delivered: the number or amount of intended units of each intervention or each component delivered or provided ${ }^{(58)}$.

7. Exposure (also called dose received): the extent to which participants actively engage with, interact with, are receptive to, and/or use materials or recommended resources ${ }^{(58)}$.

lack of knowledge, low confidence in performing certain feeding practices, and inaccurate beliefs about feeding ${ }^{(5)}$. Children who experience inappropriate feeding practices, particularly during the first 6-12 months of life, are at high risk of malnutrition, growth faltering and stunting ${ }^{(6-8)}$.
Interventions to encourage optimal IYCF practices are thus a promising strategy to prevent malnutrition in childhood and improve physical growth ${ }^{(6-9)}$. Previous IYCF interventions, which typically target expectant mothers or mothers with infants between 0 and 24 months old, have addressed the following behaviours: exclusive breast-feeding; appropriate and timely introduction of safe, nutritious complementary foods; and the proper preparation of infant foods and/or use of micronutrient supplements $^{(8)}$. IYCF interventions may be delivered via individual or community-based nutrition education sessions or home visits by community health workers or volunteer peer educators ${ }^{(9)}$. A nutrition education approach allows participants to develop a set of cognitive, affective and physical skills ${ }^{(10)}$ and is effective in encouraging optimal psychosocial factors and IYCF practices among caregivers in $\mathrm{LMIC}^{(6-11)}$. Previous authors have identified best practices in the design, implementation and evaluation of nutrition education interventions focused on $\operatorname{IYCF}^{(8,9,11)}$, which align with recommendations from the broader nutrition and health education fields ${ }^{(10,12,13)}$. For example, the use of formative research to understand the needs of the target audience, a formal theory of behaviour change and behaviour-specific messages may increase the effectiveness of interventions ${ }^{(8,9)}$. In particular, the use of theory during the design of an intervention provides several benefits to researchers and practitioners, such as making explicit the proposed pathway or mechanism for an intervention to change behaviour and facilitating replication in future studies ${ }^{(14)}$.

Yet there is concern about the ability to scale up IYCF interventions given the lack of capacity among frontline nutrition and health workers ${ }^{(15)}$. While not a new delivery platform for nutrition education ${ }^{(16)}$, mass media have recently enjoyed renewed interest as a means to expand the reach (especially to rural, inaccessible areas) and improve the cost-effectiveness of traditional approaches $^{(17,18)}$. Mass media generally include radio, print (e.g. newspapers, pamphlets, posters), loudspeakers on cars, telephones (including SMS (text) and voice messages), videos and, more recently, Internet and smartphone software applications. These platforms provide the opportunity to educate and motivate individuals who might otherwise have been missed by traditional approaches.

There has been a concurrent expansion of scientific literature describing applications of mass media for behaviour change. Yet previous reviews have been narrowly focused on developed countries, specific continents $^{(19)}$, the type of platforms used ${ }^{(20)}$ or behaviours other than IYCF, such as health services utilization, HIV treatment, family planning, and fruit and vegetable consumption $^{(21)}$. Four recent reviews of mass media did not focus exclusively on IYCF interventions or describe intervention design and implementation ${ }^{(17,22-24)}$. A comprehensive synthesis of the theories used to design and implement behaviour change interventions within 
mass media platforms remains an unfilled gap in the literature.

The objective of the current systematic review was to describe the design, implementation and effectiveness of recent interventions that include mass media components focused on improving IYCF practices and related psychosocial factors (including knowledge, attitudes and beliefs) among caregivers of children aged 0-24 months within LMIC and relative to a control group. The review is guided by previously identified design frameworks ${ }^{(10,12,13)}$ and suggested reporting conventions ${ }^{(9)}$.

\section{Methods}

The present review includes a systematic search of the peer-refereed and grey literature, in accordance with the Preferred Reported Items for Systematic Reviews and Meta-Analyses (PRISMA) Statement ${ }^{(25)}$. The protocol for the review was registered in PROSPERO (CRD42015017536). The search was constructed using the following PICO format: Population (caregivers of children aged 0-24 months), Intervention (behaviour change interventions including mass media and/or nutrition education), Comparator (usual care or no-intervention), Outcome (IYCF practices and/or related psychosocial factors) and Context (LMIC).

\section{Study identification}

Searches were conducted within PubMed, Embase and PsycINFO databases and within Google (www.google.com) to identify records describing interventions with mass media components targeting IYCF knowledge, attitudes and practices in LMIC. Searches were performed in July 2016 with the assistance of a medical librarian using the following terms: ('infant and young child feeding' or 'infant nutrition' or 'child nutrition') AND ('nutrition education' or 'health education' or 'behaviour change' or 'behaviour change communication') AND ('knowledge' or 'attitudes' or 'beliefs' or 'practices' or 'behaviours'). The searches were constructed first in PubMed and adapted for subsequent databases and the grey literature search in Google. In addition, hand searches of the reference lists were performed using previously identified reviews ${ }^{(6-11)}$ and all records that received a full-text review in the present study. Experts ( $n$ 4) from non-governmental and normative organizations were consulted to identify additional records.

\section{Study screening and eligibility}

Eligibility criteria for all identified records, including those identified in the grey literature, included: (i) LMIC setting, as defined by the World Bank ${ }^{(26)}$; (ii) interventions with a mass media component (with or without nutrition education); (iii) pre-post evaluations (with or without a control group); (iv) assessed IYCF knowledge, attitudes, beliefs and/or practices; (v) written in English; and (vi) published between 2000 and present, to align with the adoption of the Millennium Development Goals. Studies conducted in acute, hospital-based settings or in humanitarian aid situations were excluded. Conference abstracts were considered for the review, and corresponding authors were contacted for additional information.

Identified records were exported into EndNote version X5 (Thomson Reuters, Philadelphia, PA, USA; 2011) and duplicates were removed. An online software platform, Covidence (Veritas Health Innovation, Deerfield, IL, USA), was used to manage the screening of records. Two investigators (M.M.G. and Q.O.) independently reviewed the titles and abstracts of all records (in cases where no abstract was available, investigators read the entire article). After removing records that did not meet the inclusion criteria, the full text of the remaining articles was reviewed against our eligibility criteria, and disagreements were resolved with a third investigator (S.M.D.).

\section{Data extraction and quality assessment}

The following data were extracted from each article: setting, study design, baseline characteristics of participants, use of formative research, intervention design (including the use of a design framework), use of theory, formative research, mass media and/or nutrition education delivery platform, dose delivered, participant exposure, results and funding source. All supplementary data and referenced publications from the same study were considered. Data were extracted by one investigator (M.M.G.) and reviewed by a second (S.M.D.). Disagreements were resolved with the consensus decision of a third investigator (Q.O. or J.F.).

\section{Quality appraisal}

The quality of each study was assessed using the Effective Public Health Practice Project (EPHPP) Quality Assessment Tool ${ }^{(27)}$. This tool is appropriate for assessing the quality of randomized controlled trials, observational, case-control and pre-post studies across six domains: selection bias, study design, confounders, blinding, data collection method and withdrawals/dropouts. Across each domain, studies can be rated as weak, moderate or strong. An overall score is generated by averaging the scores on each domain: weak $(=1)$, moderate $(=2)$ or strong $(=3)$.

\section{Summary measures and synthesis}

Author reports of the primary (IYCF practices) and secondary outcomes (psychosocial factors) for each study were used as the summary measure. These included comparisons between intervention and control arms of the studies and/or comparisons between pre- and postoutcome measures. Where available, the SD and/or 95\% CI of estimates and indicators of statistical significance $(P$ value) were extracted. Given the heterogeneity in designs and outcome measures between studies, a metaanalysis was not possible. Study authors were contacted to provide additional information, when necessary. 


\section{Results}

\section{Overview of search}

A total of 4734 records were identified from the database searches and twenty-nine records were identified from the grey literature search, hand searches of recent reviews and articles considered for the present review, and consultations with experts (Fig. 1). Of these records, 4529 were retained for screening after duplicates were removed. Through screening, we excluded 3982 records on the basis of the title and proceeded to review the abstracts of 547 records. After excluding 455 on the basis of the abstract, the full texts of the remaining ninety-two records were reviewed for eligibility. Records that were duplicates ( $n 3$ ), did not publish in English ( $n$ 5), did not use a pre-post study design ( $n$ 9), did not have an LMIC setting ( $n$ 10) or did not include a mass media component ( $n$ 47) were excluded. A total of eighteen unique records (e.g. those describing a unique trial or study), representing sixteen peer-refereed articles and two conference abstracts, were included (Table 1$)^{(28-45)}$.

\section{Study setting and design}

Studies were conducted in China ( $n$ 3), Nigeria ( $n$ 2), Mexico ( $n$ 2), Pakistan ( $n$ 2), Vietnam ( $n$ 2), Bangladesh ( $n$ 1), Indonesia ( $n$ 1), Cambodia ( $n$ 1), India ( $n$ 1), Kenya ( $n$ 1), Burkina Faso ( $n$ 1) and Bolivia and Madagascar $(n 1)$. Eight studies were cluster-randomized controlled trials $^{(28,29,31,32,35,36,44,45)}$, one was an individual-randomized controlled trial ${ }^{(40)}$, six were pre-post without a control group $^{(33,34,38,41-43)}$ and three were pre-post with a control group $^{(30,37,39)}$. The longest study duration was 4 years and the shortest was 9 weeks; the modal duration was 1 year $\left(n\right.$ 5). Three studies had $<300$ participants ${ }^{(33,40,42)}$, seven had 300-1000 participants $(28,29,30,31,35,37,45)$ and eight had $>1000$ participants ${ }^{(32,34,36,38,39,41,43,44)}$.

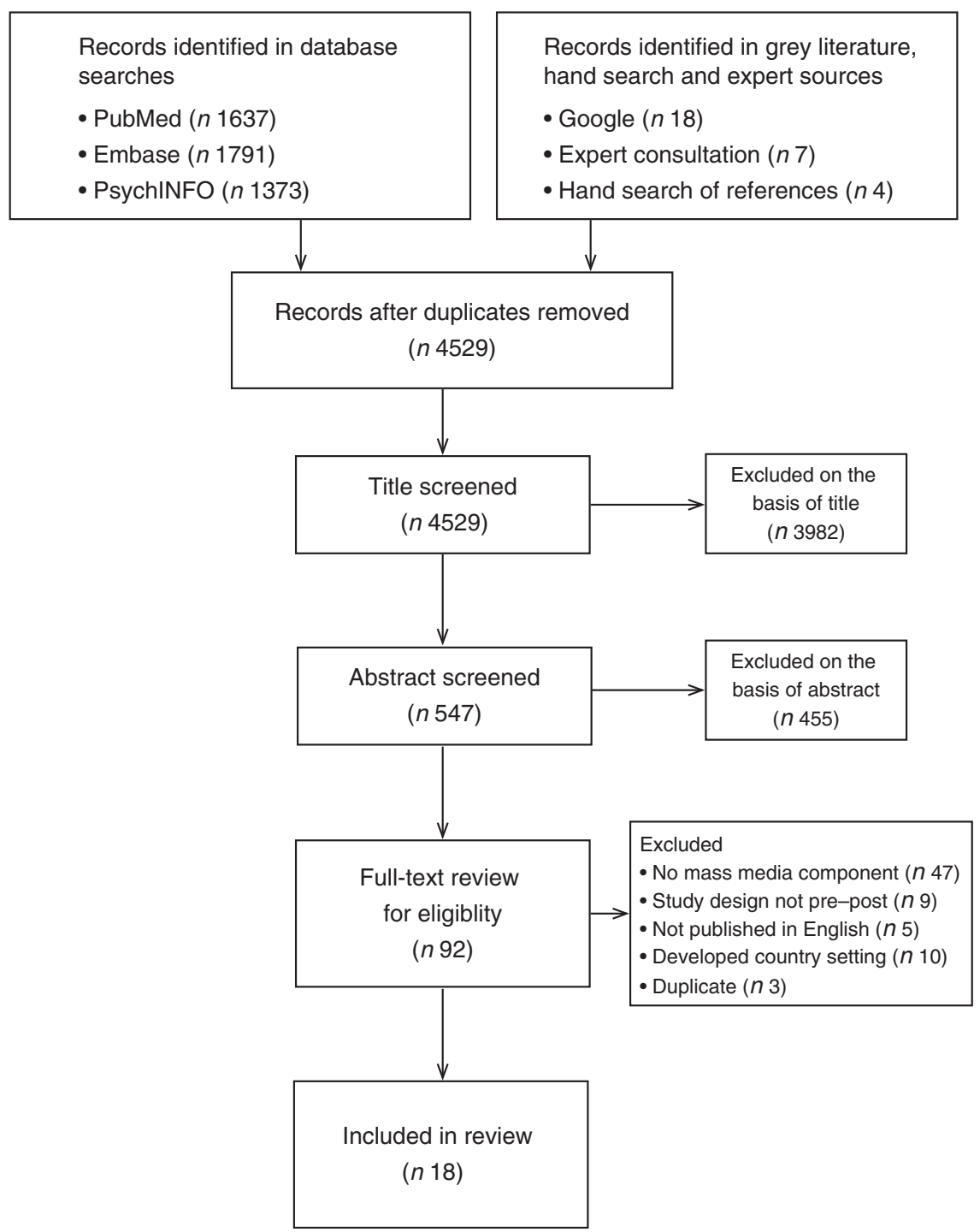

Fig. 1 Identification, screening, eligibility and inclusion of studies in the present systematic review examining mass media and nutrition education interventions for infant and young child feeding in low- and middle-income countries 
Table 1 Characteristics of nutrition education and mass media interventions that address infant and young child feeding knowledge, attitudes and practices in low- and middle-income countries

\begin{tabular}{|c|c|c|c|c|c|}
\hline Study, setting & $\begin{array}{l}\text { Study design, } \\
\text { duration }\end{array}$ & Delivery platform & Results: dose/exposure & Results: knowledge, attitudes, beliefs and practices & $\begin{array}{l}\text { Quality } \\
\text { rating }\end{array}$ \\
\hline $\begin{array}{l}\text { White et al. (2016) } \\
\text { Indonesia }\end{array}$ & $\begin{array}{l}\text { Cluster RCT } \\
3 \text { months }\end{array}$ & $\begin{array}{l}\text { Individual and group sessions, } \\
\text { TV, social media }\end{array}$ & $\begin{array}{l}51 \% \text { attended a group session } \\
25 \% \text { received a home visit } \\
32 \% \text { of participants in intervention } \\
\text { arm } 1 \text { and } 14 \% \text { in arm } 2 \text { reported } \\
\text { seeing TV advert }\end{array}$ & $\begin{array}{l}\text { Intervention arm } 1 \text { (mass media plus individual and group } \\
\text { sessions) } v \text {. control: } \\
\text { - Dietary diversity: }+1 \cdot 0 \text { point }(95 \% \mathrm{Cl} 0 \cdot 4,1 \cdot 2) \\
\text { - Vegetables: }+0.59 \text { points }(95 \% \mathrm{Cl} 0 \cdot 10,1 \cdot 07) \\
\text { - EBF: NS } \\
\text { - Unhealthy snacking: NS } \\
\text { Intervention arm } 2 \text { (mass media alone) } v \text {. control: } \\
\text { - Dietary diversity: }+0.8 \text { points }(95 \% \mathrm{Cl} 0 \cdot 6,1 \cdot 4) \\
\text { - Vegetables: NS } \\
\text { - EBF: NS } \\
\text { - Unhealthy snacking: NS } \\
\text { Intervention arm } 1 \mathrm{v} \text {. intervention arm } 2: \\
\text { - EBF at } 1 \text { month: }+22 \%(95 \% \mathrm{Cl} 17 \cdot 9,26 \%) \\
\text { - EBF at } 2 \text { months: }+18 \%(95 \% \mathrm{Cl} 14.4,22 \%) \\
\text { - EBF at } 3 \text { months: }+16 \%(95 \% \mathrm{Cl} 12 \cdot 3,19.5 \%) \\
\text { - Dietary diversity: NS } \\
\text { - Unhealthy snacking: NS } \\
\text { - Vegetables: NS }\end{array}$ & Moderate \\
\hline $\begin{array}{l}\text { Flax et al. }(2014)^{(29)} \\
\text { Nigeria }\end{array}$ & $\begin{array}{l}\text { Cluster RCT } \\
1 \text { year }\end{array}$ & $\begin{array}{l}\text { Group sessions, SMS messages, } \\
\text { songs/dramas }\end{array}$ & $\begin{array}{l}69 \% \text { attended at least } 7 \text { sessions } \\
\text { Groups met } 30(\mathrm{SD} 10) \text { times and } \\
\text { created } 17 \text { (SD 5) songs/dramas } \\
96 \% \text { of phones received messages }\end{array}$ & 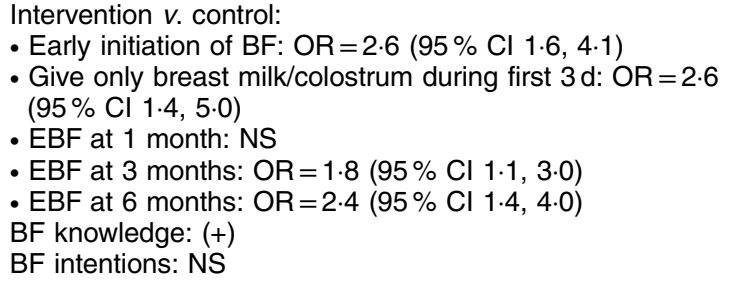 & Strong \\
\hline $\begin{array}{l}\text { Monterrosa et al. } \\
(2013)^{(30)} \\
\text { Mexico }\end{array}$ & $\begin{array}{l}\text { Pre-post with } \\
\text { control } \\
9 \text { weeks }\end{array}$ & Individual sessions and radio & $\begin{array}{l}34 \% \text { heard messages on the radio } \\
56 \% \text { received the messages at home } \\
31 \% \text { received the messages } \\
\text { at health centre }\end{array}$ & $\begin{array}{l}\text { Intervention } v \text {. control: } \\
\text { - BF frequency (past } 24 \mathrm{~h}): \mathrm{DD}=3.7(\mathrm{sD} 0.6) \\
\text { - Ever } \mathrm{BF}: \mathrm{DD}=4 \%(\mathrm{sD} 2 \%) \\
\text { - Green vegetable consumption (d/week): } \mathrm{DD}=0.6(\mathrm{sD} 0.2) \\
\text { - Beef consumption (d/week): } \mathrm{DD}=0.2(\mathrm{sD} 0.1) \\
\text { - Thicker chicken broth }(\mathrm{d} / \text { week): } \mathrm{DD}=0.6(\mathrm{sD} 0.2) \\
\text { - Thicker vegetable broth }(\mathrm{d} / \text { week): } \mathrm{DD}=0.8(\mathrm{sD} 0.4) \\
\text { BF beliefs: }(+) \\
\text { CF beliefs: }(+) \\
\text { BF attitudes: }(+) \\
\text { CF attitudes: }(+) \\
\text { BF intentions: }(+) \\
\text { CF intentions: }(+)\end{array}$ & Strong \\
\hline $\begin{array}{l}\text { Bonvecchio et al. } \\
(2007)^{(31)} \\
\text { Mexico }\end{array}$ & $\begin{array}{l}\text { Cluster RCT } \\
5 \text { months }\end{array}$ & $\begin{array}{l}\text { Individual sessions, video, print, } \\
\text { megaphones }\end{array}$ & NR & $\begin{array}{l}\text { Intervention } v \text {. control: } \\
\text { - Preparation of papilla (micronutrient supplement): }+42.9 \% \\
\text { - Feeding child papilla daily: }+64.4 \% \\
\text { - Give papilla as a snack: }+61.5 \% \\
\text { - Feed papilla to target child: }+90.0 \%\end{array}$ & Strong \\
\hline
\end{tabular}




\begin{tabular}{|c|c|c|c|c|c|}
\hline Study, setting & $\begin{array}{l}\text { Study design, } \\
\text { duration }\end{array}$ & Delivery platform & Results: dose/exposure & Results: knowledge, attitudes, beliefs and practices & $\begin{array}{l}\text { Quality } \\
\text { rating }\end{array}$ \\
\hline $\begin{array}{l}\text { Mashreky et al. } \\
(2015)^{(32)} \\
\text { Bangladesh }^{\text {(32) }}\end{array}$ & $\begin{array}{l}\text { Cluster RCT } \\
1 \text { year }\end{array}$ & Individual sessions and TV & $\begin{array}{l}19 \% \text { of mothers were exposed to } \\
\text { home visits } \\
\text { Exposure to the } 6 \text { TV commercials } \\
\text { ranged from } 31.2 \text { to } 53.9 \%\end{array}$ & $\begin{array}{l}\text { Baseline } v \text {. endline, intervention } 1 \text { (mass media only): } \\
\text { - Early initiation of } \mathrm{BF}: \mathrm{RR}=2.03(95 \% \mathrm{Cl} 1.54,2.67) \\
\text { - Introduction of } \mathrm{CF}: \mathrm{RR}=1.19(95 \% \mathrm{Cl} 1.02,1.40) \\
\text { - EBF at } 6 \text { months: NS } \\
\text { - BF knowledge: }(+) \\
\text { - CF knowledge: }(+) \\
\text { Baseline } v \text {. endline, intervention } 2 \text { (mass media plus } \\
\text { interpersonal counselling): } \\
\text { - Early initiation of } \mathrm{BF}: \mathrm{RR}=1.77(95 \% \mathrm{Cl} 1.34,2.36) \\
\text { - EBF at } 6 \text { months: NS } \\
\text { - Introduction of } \mathrm{CF}: \mathrm{RR}=1.21(95 \% \mathrm{Cl} 1.04,1.42) \\
\text { - BF knowledge: }(+) \\
\text { - CF knowledge: }(+)\end{array}$ & Moderate \\
\hline $\begin{array}{l}\text { Sun et al. }(2011)^{(33)} \\
\text { China }\end{array}$ & $\begin{array}{l}\text { Pre-post without } \\
\text { control } \\
18 \text { months }\end{array}$ & Individual sessions, TV, print & $\begin{array}{l}6470 \text { copies of a handbook containing } \\
\text { information about IYCF practices } \\
38000 \text { supplement sachets were sold }\end{array}$ & $\begin{array}{l}\text { Baseline } v \text {. endline: } \\
\text { - Early initiation of BF: }+8 \cdot 2 \% \\
\text { - BF at } 1 \text { year: NS } \\
\text { - BF at } 2 \text { years: NS } \\
\text { - Introduction of solid foods: NS } \\
\text { - Dietary diversity: }+16 \cdot 6 \% \\
\text { - Feed Fe-rich food: }+37.6 \%\end{array}$ & Moderate \\
\hline $\begin{array}{l}\text { Nguyen et al. }(2014)^{(34)} \\
\text { Vietnam }\end{array}$ & $\begin{array}{l}\text { Pre-post without } \\
\text { control } \\
26 \text { months }\end{array}$ & $\begin{array}{l}\text { Individual and group sessions } \\
\text { and radio }\end{array}$ & NR & $\begin{array}{l}\text { Intervention } v \text {. control: } \\
\text { - Early initiation of } \mathrm{BF}: \mathrm{DD}=+7.6 \% \\
\text { - EBF at } 6 \text { months: } \mathrm{DD}=+21.0 \% \\
\text { - Bottle feeding: } \mathrm{DD}=-8.8 \% \\
\text { BF knowledge: }(+) \\
\text { CF knowledge: }(+) \\
\text { BF self-efficacy: }(+) \\
\text { CF self-efficacy: }(+) \\
\text { BF intentions: }(+) \\
\text { CF intentions: }(+) \\
\text { BF beliefs: }(+) \\
\text { CF beliefs: }(+)\end{array}$ & Strong \\
\hline $\begin{array}{l}\text { Jiang et al. }(2014)^{(35)} \\
\text { China }\end{array}$ & $\begin{array}{l}\text { Cluster RCT } \\
66 \text { weeks }\end{array}$ & SMS messages & NR & $\begin{array}{l}\text { Intervention v. control: } \\
\text { - EBF at } 4 \text { months: OR }=\mathrm{NS} \\
\text { - EBF at } 6 \text { months: } \mathrm{OR}=2 \cdot 67(95 \% \mathrm{Cl} 1.45,4.91) \\
\text { - BF at } 12 \text { months: } \mathrm{OR}=\mathrm{NS} \\
\text { - Introduction of solid food before } 4 \text { months: OR }=0.27 \\
(95 \% \mathrm{Cl} 0.08,0.94) \\
\text { - Introduction of solid food before } 6 \text { months: NS }\end{array}$ & Strong \\
\hline $\begin{array}{l}\text { Sarrassat et al. }(2015)^{(36)} \\
\text { Burkina Faso }\end{array}$ & $\begin{array}{l}\text { Cluster RCT } \\
20 \text { months }\end{array}$ & Radio & $\begin{array}{l}75 \% \text { of women reported recognizing } \\
\text { at least } 1 \text { radio spot, } 54 \% \text { reported } \\
\text { listening to the long-format radio } \\
\text { programme (intervention arm) }\end{array}$ & $\begin{array}{l}\text { Intervention } v \text {. control: } \\
\text { - Timely initiation of BF: NS } \\
\text { - EBF at } 0-5 \text { months: NS } \\
\text { - CF at } 6-11 \text { months: NS } \\
\text { - Growth monitoring (past } 6 \text { months, } 0-23 \text { months old): NS }\end{array}$ & Moderate \\
\hline $\begin{array}{l}\text { Crookston et al. } \\
(2007)^{(37)} \\
\text { Cambodia }\end{array}$ & $\begin{array}{l}\text { Pre-post with } \\
\text { control } \\
1 \text { year }\end{array}$ & $\begin{array}{l}\text { Individual and group sessions, TV, } \\
\text { radio, print }\end{array}$ & $\begin{array}{l}81.5 \% \text { of participants exposed via } \\
\text { health personnel, health staff, nun, } \\
\text { wat granny, village health support } \\
\text { group, NGO staff, radio and TV }\end{array}$ & $\begin{array}{l}\text { Baseline } v \text {. endline: } \\
\text { - Early initiation of } \mathrm{BF}: \mathrm{RR}=1.62(95 \% \mathrm{Cl} 1.30,2.01) \\
\text { - EBF for past } 24 \mathrm{~h}: \mathrm{RR}=1.81(95 \% \mathrm{Cl} 1.49,2 \cdot 21) \\
\text { - EBF for past } 7 \mathrm{~d} \text { : } \mathrm{RR}=1.76(95 \% \mathrm{Cl} 1.42,2 \cdot 19) \\
\text { BF knowledge: }(+) \\
\text { BF social support: }(+)\end{array}$ & Moderate \\
\hline
\end{tabular}




\begin{tabular}{|c|c|c|c|c|c|}
\hline Study, setting & $\begin{array}{l}\text { Study design, } \\
\text { duration }\end{array}$ & Delivery platform & Results: dose/exposure & Results: knowledge, attitudes, beliefs and practices & $\begin{array}{l}\text { Quality } \\
\text { rating }\end{array}$ \\
\hline $\begin{array}{l}\text { Baker et al. }(2006)^{(38)} \\
\text { Bolivia and Madagascar }\end{array}$ & $\begin{array}{l}\text { Pre-post without } \\
\text { control } \\
3-4 \text { years }\end{array}$ & $\begin{array}{l}\text { Individual and group sessions, } \\
\text { videos, radio, TV, print }\end{array}$ & $\begin{array}{l}10 \% \text { of participants were exposed to } \\
\text { radio spots and } 69 \% \text { were exposed } \\
\text { to health workers (Bolivia only) }\end{array}$ & $\begin{array}{l}\text { Baseline } v \text {. endline: } \\
\text { - Early initiation of BF: prevalence increased from } 56 \text { to } \\
74 \% \text { (Bolivia); } 34 \text { to } 78 \% \text { (Madagascar) } \\
\text { - EBF at } 1 \text { month: prevalence increased from } 81 \text { to } 88 \% \\
\text { (Bolivia); } 86 \% \text { to } 91 \% \% \text { (Madagascar) }\end{array}$ & Weak \\
\hline $\begin{array}{l}\text { Findley et al. }(2013)^{(39)} \\
\text { Nigeria }\end{array}$ & $\begin{array}{l}\text { Pre-post with } \\
\text { control } \\
3 \text { years }\end{array}$ & $\begin{array}{l}\text { Individual and group sessions } \\
\text { and radio }\end{array}$ & $\begin{array}{l}\text { Exposure to community health } \\
\text { workers varied from } 3.5 \% \text { (control) } \\
\text { v. } 8.4 \% \text { (low-intensity group) } v \text {. } \\
14.4 \% \text { (high intensity group }\end{array}$ & $\begin{array}{l}\text { Intervention (high- and low-intensity groups) v. control: } \\
\text { - Immediate BF: } 28.3 \% \text { (control) v. } 45.7 \% \text { (low-intensity } \\
\text { group) v. } 50.9 \% \text { (high-intensity group) } \\
\text { - BF within first } 24 \mathrm{~h}: 56.1 \% \text { (control) v. } 59.1 \% \\
\text { (low-intensity group) v. } 61.1 \% \text { (high-intensity group) }\end{array}$ & Weak \\
\hline $\begin{array}{l}\text { Khayyati and Mansouri } \\
(2009)^{(40)} \\
\text { Pakistan }\end{array}$ & $\begin{array}{l}\mathrm{RCT} \\
6 \text { months }\end{array}$ & Videos & NR & $\begin{array}{l}\text { Intervention } v \text {. control } \\
\text { - EBF at } 6 \text { months: NS }\end{array}$ & Moderate \\
\hline $\begin{array}{l}\text { Kim et al. }(2015)^{(41)} \\
\text { Pakistan }\end{array}$ & $\begin{array}{l}\text { Pre-post without } \\
\text { control } \\
1 \text { year }\end{array}$ & TV, radio and print & NR & $\begin{array}{l}\text { Baseline } v \text {. endline: } \\
\text { - BF immediately after delivery: NS } \\
\text { - BF in first } 24 \mathrm{~h}: \mathrm{NS} \\
\text { - Give only breast milk/colostrum: NS } \\
\text { - EBF during first } 3 \mathrm{~d} \text { of life: NS }\end{array}$ & Strong \\
\hline $\begin{array}{l}\text { Seksaria and Sheth } \\
(2014)^{(42)} \\
\text { India }\end{array}$ & $\begin{array}{l}\text { Pre-post without } \\
\text { control } \\
5 \text { months }\end{array}$ & Individual sessions, video, print & NR & $\begin{array}{l}\text { Baseline } v \text {. endline: } \\
\text { - Is the child force-fed: }+76.09 \% \\
\text { - Is the child fed by elders: }+5 \cdot 75 \% \\
\text { - All food groups included in CF: }+6 \cdot 67 \% \\
\text { - Does the mother prepare any special foods for the child: } \\
+108.51 \% \\
\text { BF knowledge: }(+) \\
\text { CF knowledge: }(+)\end{array}$ & Weak \\
\hline $\begin{array}{l}\text { Nguyen et al. }(2016)^{(43)} \\
\text { Vietnam }\end{array}$ & $\begin{array}{l}\text { Pre-post without } \\
\text { control } \\
32 \text { months }\end{array}$ & TV & $\begin{array}{l}79.1 \% \text { of mothers in intensive } \\
\text { districts exposed to TV spots } \\
\text { (57.9\% recalled one or more } \\
\text { message); } 72.4 \% \text { of mothers in } \\
\text { non-intensive districts exposed to } \\
\text { TV spots }(68.8 \% \text { recalled one or } \\
\text { more message) }\end{array}$ & $\begin{array}{l}\text { Baseline } v \text {. endline, intervention arm } 1 \text { (mass media plus } \\
\quad \text { counselling): } \\
\text { - EBF at } 6 \text { months: }+26 \% \\
\text { BF knowledge: }(+) \\
\text { BF beliefs: }(+) \\
\text { BF self-efficacy: }(+) \\
\text { BF social norms: }(+)\end{array}$ & $N / A^{*}$ \\
\hline $\begin{array}{l}\text { Zhou et al. }(2016)^{(44)} \\
\text { China }\end{array}$ & Cluster RCT & SMS messages & $\begin{array}{l}92.4 \% \text { of caregivers reported that } \\
\text { they had regularly received and } \\
\text { read the daily messages }\end{array}$ & $\begin{array}{l}\text { Intervention } v \text {. control: } \\
\text { - Compliance to micronutrient supplement: marginal } \\
\text { effect }=0.10 ; 95 \% \mathrm{Cl}=0.03,0.16 \\
\text { - Anaemia rate: } \text { marginal effect }=-0.07 ; 95 \% \mathrm{Cl}-0.12,-0.01 \text { ) }\end{array}$ & Strong \\
\hline $\begin{array}{l}\text { Sellen et al. }(2014)^{(45)} \\
\text { Kenya }\end{array}$ & $\begin{array}{l}\text { Cluster RCT } \\
3 \text { months }\end{array}$ & SMS messages & NR & $\begin{array}{l}\text { Intervention } v \text {. control: } \\
\text { - BF initiated within } 1 \mathrm{~h} \text { : NS } \\
\text { - Onset of lactation > } \mathrm{d} \text { : NS } \\
\text { - Exclusive BF at } 3 \text { months: OR }=2.77(95 \% \mathrm{Cl} 1.44,5 \cdot 32)\end{array}$ & $N / A^{*}$ \\
\hline
\end{tabular}

RCT, randomized controlled trial; TV, television; IYCF, infant and young child feeding; NR, not reported; NGO, non-governmental organization; EBF, exclusive breast-feeding; (+), increase; DD, difference in difference; BF, breast-feeding; CF, complementary feeding; RR, relative risk; N/A, not applicable.

"We did not evaluate the quality of these studies as they are described in conference abstracts. 


\section{Study quality}

The quality of studies was categorized as weak (n 3 $)^{(38,39,42)}$, moderate $(n \text { 6 })^{(28,32,33,36,37,40)}$ and strong $(n 7)^{(29,30,31,34,35,41,44)}$ (we did not evaluate the quality of the two studies described in conference abstracts). A key limiting component of the quality of studies in the current review was the design, wherein only nine studies met the 'strong' criteria for utilizing a randomized $\operatorname{design}^{(28,29,31,32,35,36,40,44,45)}$. Of the studies utilizing a cluster-randomized design ${ }^{(28,29,31,32,35,36,44,45)}$, more than half employed an appropriate statistical analysis method to account for clustering ${ }^{(28,29,31,36,44)}$. A majority of studies did not describe the blinding status of outcome assessors and/or participants, leading to a moderate rating for this component. The validity and reliability of data collection methods was also a key component limiting the quality of included studies: thirteen of the included studies used a data collection instrument with validity or reliability for the primary outcome $e^{(28,30,31,33-37,41-45)}$, but most studies did not describe both the validity and reliability of the instrument.

\section{Impact on infant and young child feeding practices}

All but three studies demonstrated a positive impact on IYCF practices ${ }^{(36,40,41)}$. These three studies only used mass media platforms to deliver messages and did not have nutrition education components. In the 20-month radio campaign described in Sarrasset et al., there were no increases in the rates of early initiation of breast-feeding, exclusive breast-feeding or appropriate complementary feeding practices among women with children aged $<5$ years $^{(36)}$. In Khayyati and Mansouri, training videos for breast-feeding did not result in increased rates of exclusive breast-feeding at 6 months ${ }^{(40)}$. Kim et al. evaluated a 1-year television campaign and observed no significant increase in the timely initiation of breast-feeding, provision of colostrum or exclusive breast-feeding for the first $3 \mathrm{~d}$ after birth $^{(41)}$.

Six studies reported an increased prevalence of early initiation of breast-feeding ${ }^{(29,33,34,37-39)}$. In Flax et al., SMS messages delivered via cell phones resulted in increased odds of timely initiation of breast-feeding (OR $=2 \cdot 6 ; 95 \%$ CI $1 \cdot 6,4 \cdot 1)$ as compared with control ${ }^{(29)}$. The radio and education intervention described in Crookston et al. resulted in an increase in the prevalence (relative risk $=$ 1.62; $95 \%$ CI 1.30, 2.01) compared with control ${ }^{(37)}$. Across the two countries included in Baker et al., prevalence of early breast-feeding initiation increased from 56 to $74 \%$ (Bolivia) and from 34 to $78 \%$ (Madagascar) $^{(38)}$. In Findley et al., the prevalence increased from 28.3 to $45.7 \%$ (lowintensity intervention arm) and 50.9\% (high-intensity arm $)^{(39)}$. The intervention described in Nguyen et al. resulted in an increase in the timely initiation of breastfeeding relative to control (difference-in-difference $=7.6$ $\%)^{(34)}$. The social marketing campaign described by Sun et al. increased prevalence from 8.6 to $16 \cdot 8 \%{ }^{(33)}$.
Four studies reported improvements in the prevalence of exclusive breast-feeding at 6 months of age ${ }^{(29,34,35,43)}$. In Flax et al., the prevalence of exclusive breast-feeding at 6 months increased relative to control $(\mathrm{OR}=2 \cdot 4 ; 95 \% \mathrm{CI}$ $1 \cdot 4,4 \cdot 0)^{(29)}$. Jiang et al. reported that an SMS campaign for mothers resulted in an increased prevalence of exclusive breast-feeding at 6 months relative to control $(\mathrm{OR}=2 \cdot 67$; $95 \%$ CI $1.45,4.91)^{(35)}$. Nguyen et al. reported a $21 \%$ increase in prevalence of exclusive breast-feeding for children up to 6 months within the intensive intervention arm relative to the non-intensive intervention $\operatorname{arm}^{(34)}$. Nguyen et al. reported a $26 \%$ increase in exclusive breastfeeding at 6 months among mothers who were exposed to television spots and counselling ${ }^{(43)}$.

Five studies reported increases in the prevalence of appropriate complementary feeding practices ${ }^{(30,32,33,35,42)}$. In Monterrosa et al., mothers were more likely to prepare and feed children vegetable and chicken broths of thicker consistency after receiving a scripted-message intervention delivered via nurses and radio ${ }^{(30)}$. Mashreky et al. reported an improvement in the age of introduction of first complementary food $^{(32)}$. Sun et al. and Seksaria and Sheth reported an increase in the dietary diversity of complementary foods ${ }^{(33,42)}$. In Jiang et al., mothers who received SMS messages were less likely to introduce solid foods before 4 months (OR $=0 \cdot 27 ; 95 \%$ CI 0.08, 0.94) ${ }^{(35)}$.

Three studies reported more frequent use of a micronutrient supplement ${ }^{(31,33,44)}$. In Bonvecchio et al., a mass media intervention increased the correct preparation $(+42.9 \%$ relative to control) and frequency of use $(+64.4 \%$ relative to control) of a micronutrient supplement prepared in a mix of powdered milk ${ }^{(31)}$. The social marketing and mass media intervention described in Sun et al. increased purchase (13.5\% of sample) and use (55.6\% of sample) of a micronutrient supplement ${ }^{(33)}$. Likewise, Zhou et al. reported greater compliance to the micronutrient supplement regimen among those in the SMS message group as compared with the control (marginal effect $=$ $0 \cdot 10 ; 95 \%$ CI $0 \cdot 03,0 \cdot 16)^{(44)}$.

Five studies allowed for comparisons of a nutrition education intervention alone and nutrition education integrated with mass media ${ }^{(28,34,32,44,45)}$. In two of these studies $^{(28,34)}$, an integrated approach appeared more effective than mass media alone for improving breastfeeding practices. In White et al., participants in the integrated arm reported a $22 \%$ (95\% CI 18, 26\%) greater increase in the prevalence of exclusive breast-feeding at 1 month than participants who received mass media alone ${ }^{(28)}$. The integrated arm of the study described in Nguyen et al. had increases in the prevalence of early initiation of breast-feeding (difference-in-difference $=$ $7 \cdot 6 \%)$ and exclusive breast-feeding at 6 months (difference-in-difference $=21.0 \%$ ) and a decrease in the rate of bottle-feeding (difference-in-difference $=8.8 \%)^{(34)}$. In the remaining studies, intervention groups displayed similar improvements in IYCF practices. In Mashreky et al., the 
integrated and mass media only intervention groups reported similar improvements in IYCF practices compared with baseline ${ }^{(32)}$. In Kenya, Sellen et al. reported similar improvements in the prevalence of exclusive breast-feeding at 3 months among groups receiving SMS messages as those assigned to peer-led support groups ${ }^{(45)}$. Similarly, caregivers receiving micronutrient supplements plus SMS messages displayed similar improvements in the prevalence of anaemia as those receiving micronutrient supplements plus one-on-one education in Zhou et al. ${ }^{(44)}$.

None of the studies examined the impact of the intervention on physical growth, morbidity or mortality outcomes. One study found that the use of SMS messages to promote compliance to micronutrient supplementation resulted in a reduced likelihood of anaemia among children in the intervention group (marginal effect $=-0 \cdot 07$; $95 \% \mathrm{CI}-0 \cdot 12,-0 \cdot 01)^{(44)}$. Two studies reported the costs of delivering the intervention: Nguyen et al. estimated a cost of \$US 0.13 per woman reached by the intervention ${ }^{(34)}$ and Baker et al. reported a cost-benefit estimate of \$US 2.33 per each new breast-feeding initiate ${ }^{(38)}$.

\section{Impact on psychosocial factors}

Six studies measured intervention impacts on psychosocial factors, all of which reported improvements in one or more factor $^{(29,32,34,37,42,43)}$. Four studies reported improvements in knowledge about duration of exclusive breast-feeding up to 6 months ${ }^{(29,32,37,42)}$. One study reported improvements in knowledge of specific complementary feeding behaviours such as providing water and formula and age at introduction of complementary foods ${ }^{(34)}$. Three studies measured behavioural intentions for breast- and complementary feeding practices $^{(29,30,34)}$. Flax et al. reported no improvement in participants' intention to initiate breast-feeding in first hour of life, provide only colostrum or exclusively breast-feed in the first 6 months ${ }^{(29)}$. Monterrosa et al. reported improvements in intentions to feed vegetables, beef and thickened broths to children ${ }^{(30)}$ and Nguyen et al. reported improvements in intentions to feed breast milk in the first $3 \mathrm{~d}$ and first 6 months of life ${ }^{(34)}$. Two studies reported improvements in participants' perceptions of normative beliefs regarding breast-feeding and complementary feeding practices ${ }^{(30,34)}$. One study reported an increase in caregiver perceptions of breast-feeding self-efficacy ${ }^{(34)}$.

\section{Intervention design}

One study used a systematic design procedure for the intervention: White et al. used the Behaviour Centred Design model to develop an intervention to encourage IYCF practices among mothers in East Java, Indonesia ${ }^{(28)}$. The authors of four studies explicitly mentioned a formal behaviour change theory for the intervention, including the Behaviour Centred Design theory ${ }^{(28)}$, the Theory of Planned Behaviour ${ }^{(30)}$, Saturation Theory ${ }^{(36)}$ and Adult Learning Theory ${ }^{(37)}$. In the remaining studies, a formal behaviour change theory was not reported, although some mentioned a potential pathway or mechanism. Two studies provided a formal programme impact pathway ${ }^{(34,36)}$.

\section{Use of formative research}

Nine studies explicitly mentioned the use of formative research, but the sources and methods were varied. Four of these studies provided explicit detail on what types of information were gleaned from formative research and how it was used in developing the intervention $^{(28,30,31,36)}$. White et al. used several methods, including motive mapping, video ethnography, attribute ranking exercises, inventories of personal belongings and daily scripts ${ }^{(28)}$. Flax et al. collected formative information from midwives, community health workers, mothers, fathers and grandmothers ${ }^{(29)}$. Monterrosa et al. used indepth interviews and home observations of twenty-nine mothers in the study region ${ }^{(30)}$. Bonvecchio et al. conducted formative research to understand the types of communication channels that could be used to deliver messages $^{(31)}$. Mashreky et al. cited government formative research conducted as a part of a national communication plan for IYCF practices ${ }^{(32)}$. Sun et al. conducted concept testing of a micronutrient supplement using surveys ${ }^{(33)}$. Nguyen et al. cited formative research that included semistructured interviews, observations, focus group discussions and $24 \mathrm{~h}$ recalls ${ }^{(34)}$. Jiang et al. consulted guidelines from normative organizations, paediatricians, community health workers and published literature to form intervention messages ${ }^{(35)}$. Sarrasset et al. conducted a media survey to measure radio usage and conducted focus groups to form messages ${ }^{(36)}$. In the remaining studies, the use of formative research was not formally stated.

\section{Nutrition education and/or mass media delivery platforms}

In twelve studies, the target audience was primarily mothers

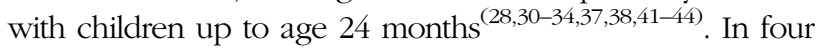
studies the audience was expectant mothers ${ }^{(29,35,40,45)}$ and in two studies the audience was mothers who had given birth in the past 5 years ${ }^{(36,39)}$. The types of mass media included: television ${ }^{(28,32-34,37,38,41)}$; print (such as newspapers, posters or pamphlets ${ }^{(28,31,33,37,38,41,42)}$; voice and/or SMS messages ${ }^{(29,35,44,45)}$; radio $^{(30,36-39,41)}$; megaphones/ loudspeakers ${ }^{(31,34)}$; $\operatorname{videos}^{(38,40,42)}$; social media ${ }^{(28)}$; and songs/dramas ${ }^{(29)}$.

In eleven studies mass media was included as a component alongside nutrition education ${ }^{(29,30-34,37-39,42,44)}$. Within these studies, nutrition education was delivered through individual sessions ( $n$ 5), in groups ( $n$ 1), or using a combination of both individual and group sessions ( $n$ 5). In eight studies, nutrition education sessions were led by a trained delivery agent, including credit officers ${ }^{(28)}$, nurses ${ }^{(30)}$, nuns ${ }^{(37)}$ or community health workers ${ }^{(32,33,34,38,39)}$. With the exception of three studies ${ }^{(30,37,34)}$, little detail was provided 
Table 2 Summary of messages and behaviours of focus from studies included in the current systematic review of mass media and nutrition education interventions in low- and middle-income countries

Study, setting Behaviours of focus/messages

White et al. $(2016)^{(28)}$

Indonesia

(i) Improved dietary diversity of complementary food. (ii) The reduction in unhealthy snacks through the

Flax et al. (2014) $)^{(29)}$

Nigeria promotion of healthy alternatives. (iii) Exclusive breast-feeding until 6 months.

(i) Breast-feed babies as soon as they are born - within the first hour. (ii) Breast-feeding the baby as soon as it is born helps the mother's breasts make enough milk for the baby and makes the mother's womb contract to stop her from bleeding. (iii) Breast-feed babies within $1 \mathrm{~h}$ of birth to make sure they get the first 'yellow milk' or colostrum. (iv) A baby does not need any other food, drinks or water before or after the colostrum. Colostrum contains all the nutrition a new baby needs and helps keep the baby from getting sick. (v) Give only breast milk until the baby is 6 months old. No other foods or drinks, not even water, are necessary. (vi) Breast-feed the baby often, during the day and night, whenever the baby wants. (vii) Allow the baby to empty one breast before offering the other breast. (viii) To breast-feed better, hold the baby's head and body in a straight line and support the baby's head with your hand or arm. (ix) To breast-feed better, make sure your baby gets a good mouthful of breast. The baby's mouth should be wide open and the lips turned out. The lower lip should be curled back and the baby's chin should be touching the mother's breast. (x) Begin feeding your baby soft, thick, mushy foods at 6 months, while continuing to breast-feed for up to 2 years and beyond. (xi) If you are HIV+ or think you may be HIV+, consult a health worker for advice about breast-feeding so you can avoid passing the disease to your baby through your breast milk.

Monterrosa et al. $(2013)^{(30)}$ Mexico

(i) Many think that breast milk after 6 months does not feed the baby, but this is not the case. Breast milk always has vitamins and special proteins that nourish your baby. In addition to feeding healthy foods beginning at 6 months, nourish your baby with your milk from birth to 2 years. (ii) Your baby's stomach is small, like the size of this cup. If you feed your baby broth, you take up space in her stomach and you don't nourish her well. Every day, prepare your baby thick foods so that she grows strong and healthy. A thick food is one that does not fall easily from the spoon (show the spoon with the food from the jar) and that you can prepare as (pap, mashed or chopped, specified according to the age of the child). (iii) To nourish your baby, cook one of these vegetables, like spinach, swiss chard, huauzontle pulp or purslane every day. These vegetables have vitamins that strengthen their development. Prepare vegetables as (pap, mashed or chopped, specified according to the age of the child). (iv) To prevent anaemia, starting at 6 months, it is important to feed your baby tastes of beef, chicken thigh or leg, and fish. A taste is like the size of your two thumbs together. As your baby grows older and eats more, you can give her a bigger portion. Many mothers are afraid that the baby may choke on the meat. So this does not happen, prepare these foods in pap until the baby is 1 year old and afterwards cut the foods into very small pieces. Every time you prepare beef, chicken thigh or leg, and fish for your family, save a small piece for your baby. If you give these foods very often you will prevent anaemia. It is very common for baby to reject or dislike vegetables and meats. But for your baby to learn to eat them, you must insist and give them until she accepts them. Be patient and offer them with love, without forcing your baby to eat them or reprimanding her. This way you help your baby be well nourished.

Bonvecchio et al. $(2007)^{(31)}$

Mexico

(i) Prepare papilla (micronutrient supplement) with 4 tablespoons $(59.2 \mathrm{ml}$ ) of the powder and 3 tablespoons ( $44.4 \mathrm{ml}$ ) of water. (ii) Give papilla to your child every day. (iii) Give papilla to your child between meals, specifically between breakfast and dinner (the comida, which is best translated as dinner, is the main family meal, which usually is eaten in early or mid-afternoon). (iv) Give papilla only to target children.

Mashreky et al. (2015) $)^{(32)}$

Bangladesh

(i) Timing of breast-feeding initiation. (ii) Exclusive breast-feeding for 6 months. (iii) Misperception of 'insufficient breast milk'. (iv) Quantity and frequency of complementary feeding. (v) Variety of foods particularly animal foods. (vi) Poor appetite. (vii) Father's support.

Sun et al. (2011) ${ }^{(33)}$

China

Nguyen et al. (2014) $)^{(34)}$

Vietnam

Caregivers were educated about infant and young child feeding (including use of a micronutrient supplement).

(i) Exclusive breast-feeding promotion during the third trimester of pregnancy. (ii) Exclusive breast-feeding support at the time of delivery. (iii) Exclusive breast-feeding management during the first 6 months of life. (iv) Complementary feeding education during the ages of 4-5.9 months. (v) Complementary feeding management during the ages of 6-24 months.

Jiang et al. (2014) $)^{(35)}$ China

(i) Preparation for breast-feeding, instructions for breast-feeding after vaginal delivery or caesarean delivery, tips for avoiding infant reflux. (ii) Rapid response to problems of breast-feeding initiation, specific guidance for women who had caesarean section delivery. (iii) Encouragement for exclusively breast-feeding and advice for not starting complementary foods during this period. For mothers who would return to work soon, encouragement and advice for continuing breast-feeding. For mothers who go back to work, how to adapt to their work environment and continue breast-feeding. For mothers who still breast-feed exclusively, continue to breast-feed exclusively until 6 months and prepare for starting solid foods at 6 months. Encouragement for continuing breast-feeding and adopting appropriate infant feeding practices.

Sarrassat et al. (2015) ${ }^{(36)}$ (i) Exclusive breast-feeding in 0- to 5-month-olds. (ii) Complementary feeding in 6- to 11-month-olds. (iii) Growth Burkina Faso monitoring in 0 - to 23 -month-olds.

Crookston et al. (2007) $)^{(37)}$ Optimal infant feeding behaviours including early initiation of breast-feeding, frequent feeding, exclusive breastCambodia

Baker et al. (2006) $)^{(38)}$

Bolivia and Madagascar

Findley et al. (2013) ${ }^{(39)}$

Nigeria

Khayyati and Mansouri $(2009)^{(40)}$

Pakistan

Kim et al. (2015) ${ }^{(41)}$

Pakistan feeding for 6 months, breast-feeding for at least 2 years, continued breast-feeding during childhood illnesses and the appropriate introduction of complementary foods.

Timely initiation of breast-feeding and exclusive breast-feeding.

Timely initiation of breast-feeding.

The importance of exclusive breast-feeding, the technique of breast-feeding, probable problems in breastfeeding and complementary nutrition of infants.

Early initiation of breast-feeding and giving colostrum to the newborn; exclusive breast-feeding for the first 6 months. 
Table 2 Continued

\begin{tabular}{ll}
\hline Study, setting & Behaviours of focus/messages \\
\hline $\begin{array}{l}\text { Seksaria and Sheth } \\
(2014)^{(42)}\end{array}$ & To promote breast-feeding and complementary feeding practices among women. \\
$\begin{array}{l}\text { India } \\
\text { Zhou et al. (2016) }\end{array}$ (44) & $\begin{array}{l}\text { (i) Remember to give baby a vitamin packet! Vitamin packets can be added to porridge, vegetables, noodles, } \\
\text { water, milk, juice or soup. (ii) Don't forget to add a vitamin packet to baby's food today, it can make your baby } \\
\text { grow up to be taller and stronger! (iii) Remember to give baby a vitamin packet today! When you add the } \\
\text { vitamin packet, make sure that the porridge, vegetables, noodles, water, milk, juice or soup isn't too hot! (iv) A } \\
\text { friendly reminder to add a vitamin packet to baby's food today - it can make baby healthier and less likely to } \\
\text { get sick! (v) It's time for baby's vitamin packet again! Don't forget to add a vitamin packet to baby's food today. } \\
\text { (vi) Remember to add a vitamin packet to baby's food today - it can make baby smarter and more active! } \\
\text { (vii) Vitamin packet means balanced vitamins for baby - baby will be healthier when he eats it! A friendly } \\
\text { reminder to mix a vitamin packet into baby's soup or porridge. }\end{array}$ \\
\hline
\end{tabular}

on the content and duration of training for those delivering nutrition education or there was no mention of training $^{(38,31,42)}$. In four studies mass media was used alone without any in-person nutrition education ${ }^{(35,36,40,41)}$. Five studies included separate intervention arms for mass media and nutrition education components $28,32,34,44,45)$.

All studies used messages encouraging specific IYCF practices (Table 2). Three studies included a focus on the provision of micronutrient supplements ${ }^{(31,33,44)}$ and the remaining studies included messages on the timely initiation of breast-feeding, exclusive breast-feeding for the first 6 months of life and/or appropriate complementary feeding. Two studies relied on scripted messages, which were provided in full in their published report ${ }^{(29,30)}$, and one study provided the content of SMS messages ${ }^{(44)}$. Generally, however, all studies provided little detail regarding if and how messages were adapted for each media platform or supported with nutrition education learning techniques.

\section{Intervention dose delivered and participant exposure}

Studies provided varying detail regarding dose of nutrition education and/or mass media delivered to participants. For example, White et al. delivered three television spots daily over the course of 3 months ${ }^{(28)}$. Flax et al. reported delivering seven group sessions of 20-30 min in duration and two SMS messages per week over the course of 4 months and then two SMS messages every other week for 3 months ${ }^{(29)}$. Monterrosa et al. delivered seven radio spots (30 s each) over the course of $21 \mathrm{~d}$, with thirty additional mentions by radio hosts and five live interviews $^{(30)}$. Mashreky et al. reported that six television spots were aired six to twenty-four times per day on two national channels ${ }^{(32)}$. Sun et al. distributed 6470 copies of a handbook containing information on IYCF practices ${ }^{(33)}$. Nguyen et al. reported that each mother-child received between nine and fifteen counselling sessions (six to ten were individual and three to five were group sessions) over a 27 -month period ${ }^{(34)}$. In the radio campaign described by Sarrassat et al., 1 min spots were broadcast approximately 10 times/d, and $2 \mathrm{~h}$ interactive long-format programmes were broadcast $5 \mathrm{~d} /$ week $^{(36)}$. In Khayyati and Mansouri, mothers viewed a breast-feeding training video on at least three occasions ${ }^{(40)}$. Kim et al. reported that two television spots were aired 18972 times over the course of a year ${ }^{(41)}$. In Zhou et al., SMS messages were delivered daily to caregivers over the course of 6 months ${ }^{(44)}$.

Participants' exposure to the intervention was assessed in some of the included studies. In White et al., 32\% of participants in intervention arm 1 (television adverts and group sessions) and $14 \%$ in arm 2 (television adverts alone) reported seeing an advert, 51\% reported attending at least one group session and $25 \%$ reported having received a home visit ${ }^{(28)}$. Flax et al. reported $69 \%$ of participants attended at least seven group sessions, where a mean of 17 (SD 5) songs or dramas were created, and that cell phone SMS and voice messages were received by $96 \%$ of phones $^{(29)}$. In Monterrosa et al., 34\% of participants reported hearing scripted messages; $56 \%$ of whom received the messages from a nurse at home and $31 \%$ at a health centre $^{(30)}$. Mashreky et al. reported that $19 \%$ of mothers were exposed to home visits and exposure to each of the six television commercials ranged from 31.2 to $53.9 \%{ }^{(32)}$. In the radio campaign described in Sarrasat et al., $75 \%$ of women in the intervention group reported recognizing at least one of the radio spots, and $54 \%$ reported listening to the longformat programme ${ }^{(36)}$. Crookston et al. reported that $60 \%$ of the households in the intervention area attended education sessions and $76 \cdot 1 \%$ received counselling ${ }^{(37)}$. In Baker et al., the project in Bolivia reported that $10 \%$ of participants were exposed to radio spots and $69 \%$ were exposed to health workers ${ }^{(38)}$. Across the intervention arms described in Findley et al., exposure to community health workers varied from $3.5 \%$ (control) $v .8 .4 \%$ (low-intensity group) $v$. $14.4 \%$ (high-intensity group) ${ }^{(39)}$. Sun et al. reported that 38000 sachets of a micronutrient supplement were sold during the intervention ${ }^{(33)}$. In Kim et al., $29.5 \%$ of participants saw the television spots, $2.3 \%$ heard radio spots and $2.5 \%$ saw print media ${ }^{(41)}$. In Zhou et al., $92.4 \%$ of caregivers reported that they received and read the SMS messages ${ }^{(44)}$. 


\section{Discussion}

The current systematic review identified eighteen studies that examined the impact of nutrition education and/or mass media approaches on IYCF knowledge, attitudes, beliefs and practices. Overall, fifteen of the eighteen studies demonstrated improvements in breast-feeding practices, including the timely initiation of breast-feeding and breast-feeding at 1 month, 3 months and 6 months. Several studies reported improvements in specific complementary feeding practices such as improved dietary diversity, age at introduction of complementary foods and use of micronutrient supplements. Although studies were heterogeneous in the indicators assessed (which precluded a meta-analysis), all used one or more recommended by the WHO for assessing $\mathrm{IYCF}^{(46)}$.

A few of the studies included in the present review examined mass media approaches alone (without nutrition education) or directly compared a mass media approach with a combined approach. When in-person nutrition education was combined with mass media, participants generally reported greater improvements in breast- and complementary feeding practices. In three studies where mass media was used as the only approach, there were no significant improvements in IYCF practices, suggesting that mass media alone is not effective in changing behaviour. Although the trials were heterogeneous in many aspects and several authors provided limited detail on the messages used within the mass media approaches, the refrain that communication alone is not effective for behaviour change has a long history ${ }^{(47)}$. Previous authors have cautioned that mass media alone may increase awareness or knowledge, but without the proper skills, individuals are unlikely to adopt a given behaviour ${ }^{(10)}$

Less than half of studies included in the present review assessed psychosocial factors related to IYCF among caregivers. Although mass media approaches are hypothesized to be useful in shaping social normative beliefs ${ }^{(48)}$, only three studies assessed this indicator ${ }^{(30,34,43)}$. Assessing psychosocial factors may help to identify a mechanism by which mass media components interventions are working to change behaviour ${ }^{(12)}$. Previous authors have suggested that mass media approaches are useful in encouraging oneoff, episodic behaviours (e.g. vaccination) as opposed to habitual, ongoing behaviours ${ }^{(17,36)}$. While IYCF practices represent habitual, albeit periodic, behaviours, expectant mothers and mothers of infants and young children are likely different from other audiences in that they are more receptive and have a strong desire to provide proper nutrition for their children. In the studies included in the present review, there was little similarity in the methods used to measure psychosocial factors and little detail regarding the validation or psychometric properties associated with the questionnaire items used. Future studies should explore which psychosocial factors mediate the relationship between the intervention and behaviour using consistent, validated measures.

Several authors have called for the use of systematic design processes for developing intervention components, yet only one study in the present review mentioned using one. To our knowledge, multiple design frameworks exist, including the Trials of Improved Practices ${ }^{(49)}$, the DESIGN system $^{(10)}$, Behaviour Centred Design ${ }^{(28)}$ and others ${ }^{(12,13)}$. Since a majority of interventions included in the review did not use a systematic design process, we cannot draw conclusions about the effectiveness of their use, although we believe that they may allow for easier comparison of future mass media IYCF interventions.

More than half of studies in the present review used formative research, but varied in the amount of detail provided to the description of this work. Few of these studies reported specific descriptions of how formative work was used to develop intervention components. There is a great need to detail how the findings of formative research are applied to the design of messages so that others may adapt interventions in disparate contexts $^{(50)}$. Specific to mass media, formative research can be used to help provide rationale for the platforms chosen for delivering messages. In the current systematic review, we found only two instances of formative research being used to this end.

Only four studies mentioned the use of a formal theory, although some studies mentioned a potential pathway or mechanism. The absence of a formal theory does not mean interventions are atheoretical by default, but a stated theory may provide credibility to the hypothesized programme pathway. A recent systematic review of behaviour change interventions focused on fruit and vegetable intake concluded that theory-based interventions were more efficacious than those that did not use theory ${ }^{(51)}$. Further, no study included in the present review provided detail on the specific behaviour change techniques utilized in nutrition education or mass media components to encourage behaviour change. The consistent reporting of techniques can ensure that interventions are replicable and that future systematic reviews identify effective intervention components. We suggest that authors report on techniques used consistent with previously published taxonomy of behaviour change techniques ${ }^{(52)}$.

Many of the studies in the present review reported on the dose delivered and participants' exposure to messages, but few reported both. Reporting dose delivered allows researchers to identify the optimal amount of 'touch' from an intervention that is sufficient to result in behaviour changes, so as not to be wasteful of resources ${ }^{(48,53)}$. Moreover, assessing participants' exposure to the intervention allows researchers to identify the extent to which intervention messages were read, heard or otherwise interacted with by participants. For example, in studies using SMS messages, it is useful to assess and report on the number of messages sent, the number of messages 
Table 3 Reporting priorities for future research examining nutrition education and mass media interventions targeting infant and young child feeding practices in low- and middle-income countries

Follow steps from a systematic conceptual design framework, including the Trials of Improved Practices ${ }^{(49)}$, the Nutrition Education DESIGN System ${ }^{(10)}$, Behaviour Centred Design ${ }^{(28)}$ and others ${ }^{(12,13)}$

State use of formal behaviour change theory or programme impact pathway

State use of formative research and how findings were used to develop intervention messages

Provide messages used in all mass media and nutrition education components

Categorize the content of intervention components using formal behaviour change techniques ${ }^{(55)}$

Assess and report on both the dose delivered and participant exposure to intervention

Assess and report on changes in knowledge, attitudes and beliefs associated with hypothesized programme impact pathway using validated psychosocial instruments

Assess and report on the cost-effectiveness of the intervention

received, and participants' perceptions and use of the messages. These indicators may identify essential components for the design of mass media interventions, particularly regarding the types of messages, which channels should be used to deliver message and how messages are perceived by the audience ${ }^{(48)}$.

A strength of the present review is the multiple search strategies, including a search of three academic databases and a search of the grey literature. We also registered this search a priori in PROSPERO, a registry of systematic review protocols, although we added an additional search method (consultations with experts in the fields of IYCF) to identify all eligible studies. There are also several limitations. First, there is concern about the review's timeliness, given the potential for new mass media platforms to be used to deliver IYCF messages. However, we believe that the principles of effective intervention design, including the use of a systematic design process and behaviour change theory, are applicable to all mass media platforms. Second, our extraction of data from studies is limited by the lack of published information describing intervention components. Although descriptions of interventions are often limited by space limitations in most peer-refereed journals, several avenues exist to report this information, including within online supplementary material, multiple publications or other web platforms, all of which were considered during our search. We echo previous recommendations for reporting conventions to ensure consistency and replicability of IYCF intervention studies ${ }^{(9)}$ and mass media studies ${ }^{(17)}$ (Table 3).

As governments, think-tanks and funders coalesce around mass media as a development strategy, there are concerns about the evidence base supporting their use. The current systematic review provided evidence of effectiveness of integrated mass media and nutrition education interventions for IYCF among caregivers in LMIC. Yet studies often asked a narrow question: are mass media platforms effective? To open the 'black box', future research should ask broader questions, including: in which contexts are they effective; using which types of messages; for which audiences; at what intensity; and are they synergistic with traditional approaches? An exploration of these questions may help overcome concerns about the use of mass media, including issues of literacy, participant fatigue and equity in coverage rates. Moreover, given the heightened attention to and funding for nutrition-specific interventions, more information regarding design and implementation of mass media interventions will help to meet the needs of practitioners currently working in this area ${ }^{(11,54)}$.

\section{Acknowledgements}

Financial support: This research received no specific grant from any funding agency in the public, commercial or notfor-profit sectors. Conflict of interest: The authors have no conflicts of interest to declare. Authorship: J.F. and S.M.D. provided the study concept and design; M.M.G., Q.O. and S.M.D. were responsible for acquisition and interpretation of data; M.M.G. drafted the manuscript; J.F., S.M.D. and Q.O. contributed to critical revisions of the manuscript and approved the final version; J.F. supervised all aspects of the study and provided administrative, technical and material support. Ethics of human subject participation: Not applicable.

\section{References}

1. UNICEF, World Health Organization \& The World Bank Group (2015) Joint child malnutrition estimates - levels and trends (2015 edition). http://www.who.int/nutgrowthdb/ estimates2014/en/ (accessed July 2016).

2. Black RE, Victora CG, Walker SP et al. (2013) Maternal and child undernutrition and overweight in low-income and middle-income countries. Lancet 382, 427-451.

3. Victora CG, Adair L, Fall C et al. (2008) Maternal and child undernutrition: consequences for adult health and human capital. Lancet 371, 340-357.

4. World Health Organization (2015) Essential Nutrition Actions: Improving Maternal, Newborn, Infant and Child Health and Nutrition. Geneva: WHO.

5. Balogun OO, Dagvadorj A, Anigo KM et al. (2015) Factors influencing breastfeeding exclusivity during the first 6 months of life in developing countries: a quantitative and qualitative systematic review. Matern Child Nutr 11, 433-451.

6. Bhutta ZA, Das JK, Rizvi A et al. (2013) Evidence-based interventions for improvement of maternal and child nutrition: what can be done and at what cost? Lancet 382, 452-477.

7. Shi L \& Zhang J (2011) Recent evidence of the effectiveness of educational interventions for improving complementary 
feeding practices in developing countries. J Trop Pediatr $\mathbf{5 7}$, 91-98.

8. Dewey KG \& Adu-Afarwuah S (2008) Systematic review of the efficacy and effectiveness of complementary feeding interventions in developing countries. Matern Child Nutr $\mathbf{4}$, 24-85.

9. Fabrizio CS, Van Liere M \& Pelto G (2015) Identifying determinants of effective complementary feeding behavior change interventions in developing countries. Matern Child Nutr 10, 575-592.

10. Contento IR (2013) Nutrition Education: Linking Theory, Research and Practice. Burlington, MA: Jones and Bartlett.

11. Pelto GH, Matin SL, Van Liere M et al. (2015) The scope and practice of behavior change communication to improve infant and young child feeding in low- and middle-income countries: results of a practitioner study in international development organizations. Matern Child Nutr 12, 229-244.

12. Baranowski T, Cerin E \& Baranowski J (2009) Steps in the design, development and formative evaluation of obesity prevention-related behavior change trials. Int J Behav Nutr Phys Act 6, 6.

13. Bartholomew LK, Parcel GS \& Kok G. (1998) Intervention mapping: a process for developing theory- and evidencebased health education programs. Health Educ Behav 25 , 545-563.

14. Davidoff F, Dixon-Woods M, Leviton L et al. (2015) Demystifying theory and its use in improvement. BMJ Qual Saf 24, 228-238.

15. Fanzo JC, Graziose MM, Kraemer K et al. (2015) Educating and training a workforce for nutrition in a post-2015 world. Adv Nutr 6, 639-647.

16. Manoff RK (1973) Potential uses of mass media in nutrition programs. J Nutr Educ 5, 125-129.

17. Naugle DA \& Hornick RC (2014) Systematic review of the effectiveness of mass media interventions for child survival in low- and middle-income countries.J Health Commun 19 , 190-215.

18. Annan K \& Dryden S (2015) Food and the transformation of Africa: getting smallholders connected. Foreign Affairs, November/December 2015 issue. https://www.foreignaffairs.com/articles/africa/2015-10-16/food-and-transformation-africa (accessed October 2017).

19. Aranda-Jan CB, Mohutsiwa-Dibe N \& Loukanova S (2014) Systematic review on what works, what does not work and why of implementation of mobile health (mHealth) projects in Africa. BMC Public Health 14, 188.

20. Hall CS, Fottrell E, Wilkison S et al. (2014) Assessing the impact of mHealth interventions in low- and middle-income countries what has been shown to work. Glob Health Action 7, 25606.

21. Snyder LB (2007) Health communication campaigns and their impact on behavior. J Nutr Educ Behav 39, 2 Suppl., S32-S40.

22. Higgs ES, Goldberg $\mathrm{AB}$, Labrique $\mathrm{AB}$ et al. (2014) Understanding the role of mHealth and other media interventions for behavior change to enhance child survival and development in low- and middle-income countries: an evidence review. J Health Commun 19, 164-189.

23. Lee SH, Nurmatov UB, Nwaru BI et al. (2016) Effectiveness of mHealth interventions for maternal, newborn and child health in low- and middle-income countries: systematic review and meta-analysis. J Glob Health 6, 010401.

24. Wakefield MA, Loken B \& Hornick RC (2010) Use of mass media campaigns to change health behavior. Lancet $\mathbf{3 7 6}$, 1261-1271.

25. Moher D, Liberati A, Tetzlaff J et al. (2009) Preferred Reporting Items for Systematic Reviews and Meta-Analyses: the PRISMA Statement. Ann Intern Med 151, 264-269.
26. The World Bank Group (2016) How we classify countries. http://databank.worldbank.org/data/download/site-content/ CLASS.xls (accessed July 2016).

27. Armijo-Olivo S, Stiles CR, Hagen NA et al. (2010) Assessment of study quality for systematic reviews: a comparison of the Cochrane Collaboration Risk of Bias Tool and the Effective Public Health Practice Project Quality Assessment Tool: methodological research. J Eval Clin Pract 18, 12-18.

28. White S, Schmidt W, Sahanggamu D et al. (2016) Can gossip change nutrition behavior? Results of a mass media and community-based intervention trial in East Java, Indonesia. Trop Med Int Health 21, 348-364.

29. Flax VL, Negerie M, Ibrahim AU et al. (2014) Integrating group counseling, cell phone messaging, and participantgenerated songs and dramas into a microcredit program increases Nigerian women's adherence to international breastfeeding recommendations. J Nutr 144, 1120-1124.

30. Monterrosa EC, Frongillo EA, de Cossio TG et al. (2013) Scripted messages delivered by nurses and radio changed beliefs, attitudes, intentions, and behaviors regarding infant and young child feeding in Mexico. J Nutr 143, 915-922.

31. Bonvecchio A, Pelto GH, Escalante E et al. (2007) Maternal knowledge and use of a micronutrient supplement was improved with a programmatically feasible intervention in Mexico. J Nutr 137, 440-446.

32. Mashreky SR, Rahman F, Rahman A et al. (2015) Role of mass media in increasing knowledge and practices of mothers on IYCF: findings from a community trial in rural Bangladesh. South East Asia J Public Health 5, 18-24.

33. Sun J, Dai Y, Zhang S et al. (2011) Implementation of a programme to market a complementary food supplement (Ying Yang Bao) and impacts on anaemia and feeding practices in Shanxi, China. Matern Child Nutr 7, 96-111.

34. Nguyen PH, Menon P, Keithly SC et al. (2014) Program impact pathway analysis of a social franchise model shows potential to improve infant and young child feeding practices in Vietnam. J Nutr 144, 1627-1636.

35. Jiang H, Li M, Wen LM et al. (2014) Effect of short message service on infant feeding practice findings from a community-based study in Shanghai, China. JAMA Pediatr 168, 471-478.

36. Sarrassat S, Meda N, Ouedraogo M et al. (2015) Behavior change after 20 months of a radio campaign addressing key lifesaving family behaviors for child survival: midline results from a cluster randomized trial in rural Burkina Faso. Glob Health Sci Pract 3, 557-576.

37. Crookston BT, Dearden KA, Chan K et al. (2007) Buddhist nuns on the move: an innovative approach to improving breastfeeding practices in Cambodia. Matern Child Nutr $\mathbf{3}$, $10-24$.

38. Baker EJ, Sanei LC \& Franklin N (2006) Early initiation of and exclusive breastfeeding in large-scale community based programmes in Bolivia and Madagascar. J Health Popul Nutr 24, 530-539.

39. Findley SE, Uwemedimo OT, Doctor HV et al. (2013) Comparison of high- versus low-intensity community health worker intervention to promote newborn and child health in northern Nigeria. Intl J Womens Health 5, 717-728.

40. Khayyati F \& Mansouri M (2009) The effect of training movies on exclusive breastfeeding. Pak J Med Sci 25, 434-438.

41. Kim YM, Haq Z, Soomro J et al. (2015) Case study: effects of a media campaign on breastfeeding behaviours in Sindh Province, Pakistan. World Health Popul 16, 39-45.

42. Seksaria SA \& Sheth MK (2014) Mass media campaign to improve infant and young child feeding practices amongst tribal mothers of Chikbli taluka, Gujarat. Am Int $J$ Res Human Art Soc Sci 6, 191-195. 
43. Nguyen TT, Alayón S, Nguyen PH et al. (2016) Large-scale television campaign associated with higher prevalence of exclusive breastfeeding in Vietnam. FASEB J 30, 274.8 .

44. Zhou H, Sun S, Luo R et al. (2016) Impact of text message reminders on caregivers' adherence to a home fortification program against child anemia in rural western China: a cluster-randomized controlled trial. Am J Public Health 106, 1256-1262.

45. Sellen D, Mbugua S, Webb GA et al. (2014) Cell phone based peer counseling can support exclusive breastfeeding: a randomized controlled trial in Kenya. FASEB J 28, 119.5 .

46. World Health Organization, UNICEF, US Agency for International Development, et al. (2010) Indicators for Assessing Infant and Young Child Feeding Practices. Part I: Definitions. Geneva: WHO.

47. Gillespie AH (1981) Applying communication theory in nutrition education research. J Nutr Educ 13, issue 1, S29-S33.

48. Institute of Medicine (2002) Speaking of Health: Assessing Health Communication Strategies for Diverse Populations. Washington, DC: National Academies Press.

49. The Manoff Group (2005) Trials of Improved Practices (TIPS): Giving Participants a Voice in Program Design. Washington, DC: The Manoff Group.

50. Bentley ME, Johnson SL, Wasser H et al. (2014) Formative research methods for designing culturally appropriate, integrated child nutrition and development interventions: an overview. Ann N Y Acad Sci 1308, 54-67.
51. Diep CS, Chen T, Davies VF et al. (2014) Influence of behavioral theory on fruit and vegetable intervention effectiveness among children. J Nutr Educ Behav 46, 506-546.

52. McNulty J (2013) Challenges and Issues in Nutrition Education. Rome: Nutrition Education and Consumer Awareness Group, FAO.

53. Snyder LB \& Hamilton MA (2002) Meta-analysis of US health campaign effects on behavior: emphasize enforcement, exposure, and new information, and beware the secular trend. In Public Health Communication: Evidence for Behavior Change, pp. 357-384 [R Hornik, editor]. Hillsdale, NJ: Lawrence Erlbaum Associates.

54. Pelto G, Martin SL, van Liere MJ et al. (2016) Perspectives and reflections on the practice of behaviour change communication for infant and young child feeding. Matern Child Nutr 12, 245-261.

55. Michie S, Richardson M, Johnston M et al. (2013) The behavior change technique taxonomy (v1) of 93 hierarchically clustered techniques: building an international consensus for the reporting of behavior change interventions. Ann Behav Med 46, 81-95.

56. Pan American Health Organization/World Health Organization (2003) Guiding Principles for Complementary Feeding of the Breastfed Child. Washington, DC: PAHO/WHO.

57. UNICEF (2013) Children, ICT and Development: Capturing the Potential, Meeting the Challenges, Innocenti Insight. Florence: UNICEF Office of Research.

58. Steckler A \& Linnan L (2002) Process Evaluation for Public Health Interventions and Research. San Francisco, CA: Jossey-Bass. 